\title{
A ENFERMAGEM FRANCESA: ASSISTÊNCIA E EDUCAÇÃO - CONSIDERAÇÕES ACERCA DE SUA HISTÓRIA E PERSPECTIVAS ATUAIS
}

\author{
Isabel Cristina Alves Maliskaํ, Maria Itayra Padilha², Miriam Süsskind Borenstein ${ }^{3}$, Roberta Costa4, Vitória \\ Regina Petters Gregório ${ }^{5}$, Mariana Vieira ${ }^{6}$
}

${ }^{1}$ Doutoranda pelo Programa de Pós-Graduação em Enfermagem (PEN) da Universidade Federal de Santa Catarina (UFSC). Enfermeira Assistencial do Hospital Universitário da UFSC. Santa Catarina, Brasil. E-mail: isabel.alves07@yahoo.com.br

${ }^{2}$ Doutora em Enfermagem. Professora Associado do Departamento de Enfermagem da UFSC. Pesquisadora do CNPq. Santa Catarina, Brasil. E-mail: padilha@nfr.ufsc.br

${ }^{3}$ Doutora em Enfermagem. Professora Associado do Departamento de Enfermagem da UFSC. Pesquisadora do CNPq. Santa Catarina, Brasil. E-mail: miriam@nfr.ufsc.br

${ }^{4}$ Doutora em Enfermagem. Enfermeira da unidade neonatal do Hospital Universitário da UFSC. Santa Catarina, Brasil. E-mail: robertanfr@hotmail.com

${ }^{5}$ Doutoranda pelo PEN/UFSC. Professora do Departamento de Enfermagem da UFSC. Santa Catarina, Brasil. E-mail: vitoria@ nfr.ufsc.br

${ }^{6}$ Mestre em Enfermagem. Enfermeira do Trabalho da Secretaria de Estado da Administração de Santa Catarina. Santa Catarina, Brasil. E-mail: nanyufsc@ibest.com.br

RESUMO: Trata-se de uma pesquisa documental, de natureza histórico-social, que teve como objetivo conhecer a história da educação e profissionalização da enfermagem moderna francesa, bem como as novas perspectivas para a profissão naquele país, no que se refere à estruturação, formação e organização da profissão. Foram utilizados periódicos, livros, a legislação pertinente à temática, materiais produzidos por Associações de Enfermagem francesas acerca de sua história, que, através da análise documental, chegou-se a três categorias: A enfermagem moderna na França: a influência republicana; O modelo nightingaleano na França; e A educação em enfermagem na atualidade: novas perspectivas. Conclui-se que a enfermagem francesa sofreu grandes mudanças e vem passando por um momento histórico importante, com a discussão de novas competências para a profissão, um novo currículo universitário para a enfermagem, além da implantação da Ordem Nacional de Enfermeiros, gerando repercussões políticas, sociais e científicas que darão novos rumos à profissão.

DESCRITORES: História da enfermagem. Educação em enfermagem. Educação.

\section{FRENCH NURSING: ASSISTANCE AND EDUCATION - CONSIDERATIONS CONCERNING HISTORICAL AND CURRENT PERSPECTIVES}

\begin{abstract}
This is a social-historical documental study, aiming to better understand the history of education and professionalization in modern French nursing as well as new perspectives for the profession in France with reference to the profession's structuring, formation, and organization. We used pertinent periodicals, books, decrees, laws, and materials produced by the French Nursing Associations about its history. Documentary analyses then produced three categories: Modern French nursing: the republican influence; the Nightingale model in France; and nursing education in actuality: new perspectives. The conclusion was that French nursing has suffered great changes and is going through an important historical moment with the discussion of new competencies for the profession, a new university curriculum for nursing, as well as the implantation of the National Nursing Order - creating political, social, and scientific repercussions that will give new paths to the profession.
\end{abstract}

DESCRIPTORS: History of nursing. Nursing education. Education.

\section{LA ENFERMERÍA EN FRANCIA: ASISTENCIA Y EDUCACIÓN - CONSIDERACIONES ACERCA DE SU HISTORIA Y PERSPECTIVAS ACTUALES}

RESUMEN: Se trata de una investigación documental, de naturaleza histórica y social, que tiene como objetivo conocer la historia de
la educación y profesionalización de la enfermería moderna en Francia, así como las nuevas perspectivas para la profesión en aquel
país, referente a la estructuración, formación y organización de la profesión. Para el estudio se utilizaron revistas, libros, la legislación
relativa a la temática y materiales producidos por asociaciones de enfermería francesas acerca de su historia. Por medio del análisis
documental se obtuvieron tres categorías: la enfermería moderna en Francia: la influencia republicana; el modelo Nightingaleano en
Francia; y la educación en enfermería en la actualidad: nuevas perspectivas. Se concluye que la enfermería francesa sufrió grandes
cambios y pasa por un momento histórico importante, con la discusión de nuevas competencias para la profesión, un nuevo currículo
universitario para enfermería, además de la implantación de la Orden Nacional de Enfermeros, que ha producido repercusiones
políticas, sociales y científicas que darán nuevos rumbos a la profesión. DESCRIPTORES: Historia de la enfermería. Educación en enfermería. Educación. 


\section{INTRODUÇÃO}

A profissão da enfermagem na França tem sido marcada por uma história de luta por reconhecimento, valorização e desenvolvimento da profissão, culminando, no momento atual, por conquistas que podem dar novos e decisivos rumos à profissão naquele país. Tendo nosso interesse focado na história da enfermagem nacional e internacional, ao participarmos do Grupo de Estudos de História do Conhecimento de Enfermagem e Saúde (GEHCES), vinculado ao Programa de Pós Graduação em Enfermagem da Universidade Federal de Santa Catarina (PEN/UFSC), percebemos que sabemos muito pouco acerca da história da enfermagem de outros países. O conhecimento das correntes sócio-econômicas, culturais e políticas que influenciam e influenciaram o percurso da história da profissão da enfermagem nos possibilita elucidar o contexto das transformações de nossa prática. Deste modo, o registro da história da enfermagem em suas diversas faces e fases, desenvolvido nas diferentes regiões do mundo, pode ser um exercício de autoconhecimento, uma vez que a relação da profissão da enfermagem com a sociedade é permeada por conceitos que se estabeleceram na trajetória histórica da profissão, influenciando até hoje a concepção de qual seu significado enquanto profissão da saúde. ${ }^{1}$

Por esse motivo, resolvemos estudar um pouco da realidade da enfermagem na França, considerando que a enfermagem brasileira, especialmente a pré-profissional, teve forte influência francesa, em decorrência da vinda das Irmãs de Caridade de São Vicente de Paulo, em 1852, para o Brasil. Estas vieram para assumir a direção dos serviços hospitalares e os cuidados de enfermagem a serem ministrados na Santa Casa de Misericórdia do Rio de Janeiro, expandindo posteriormente para outras instituições sob encargo da Ordem da Misericórdia, além de outras instituições públicas e privadas. ${ }^{2}$ Gradativamente, esta e outras irmandades francesas continuaram a vir para o Brasil e assumiram atividades em outros hospitais e escolas de enfermagem brasileiras. ${ }^{3}$ As ações de enfermagem passaram a ser gradativamente institucionalizadas e modeladas pelo espírito de religiosidade, e foram introduzidas mais nitidamente as mulheres no cuidado aos doentes, como um trabalho de valor altruísta.

A profissionalização de enfermagem na França ocorreu paralelamente à instalação da Terceira República (1870-1940) naquele país, período em que se dissemina um laicismo progressivo nas instituições, surgindo a necessidade de formar novos cuidadores, que substituíssem progressivamente as Irmãs de Caridade que atuavam nos hospitais. Esperava-se que as novas enfermeiras fossem necessariamente laicas e pudessem ministrar os tratamentos prescritos aos doentes, com algum conhecimento formal. Neste contexto, surgiram dois projetos para formação das enfermeiras, diferentes e convergentes, resumindo-se no modelo republicano das Escolas da Assistência Pública de Paris e o modelo Nightingaleano distribuído pela província da França. Ainda nos dias atuais, identifica-se, na formação dos futuros enfermeiros, uma herança da oposição entre esses dois modelos; o primeiro que aponta para a necessidade da enfermeira servir o doente, e o modelo anglo-saxônico, fundado a partir de uma organização coletiva e estruturada, contando com ferramentas como o dossiê de cuidados, a elaboração de diagnósticos, o posicionamento flexível entre enfermeira e médico, a busca da autonomia e da competência técnica. ${ }^{4}$

Atualmente, na França, há uma preocupação crescente em formar profissionais que estejam inseridos em um "saber ser", e que estejam preparados para as mudanças que a profissão vem passando nos últimos tempos, vislumbrando-se também aquelas que estão por vir. A enfermagem passa por um momento histórico importante, pela recente formação do Conselho Nacional da Ordem dos Enfermeiros, órgão oficial que passou a representar a profissão de enfermagem naquele país a partir de janeiro de 2009. Discute-se a determinação de novas competências para os enfermeiros, com a implantação de uma "prática de enfermagem avançada", e encontra-se em discussão a formulação de um currículo universitário para enfermagem, com possibilidade de acesso ao sistema chamado de LMD (Licenciatura, Mestrado e Doutorado). ${ }^{4-5}$

Estes importantes acontecimentos têm gerado repercussões políticas, sociais e científicas que darão novos rumos à profissão. Neste contexto, traçamos como objetivo deste estudo conhecer a história da educação e profissionalização da enfermagem moderna francesa, bem como as novas perspectivas para a profissão naquele país, no que se refere à estruturação, formação e organização da profissão.

\section{METODOLOGIA}

Trata-se de uma pesquisa documental, de natureza histórico-social, que versa sobre o período moderno da profissão de enfermagem na 
França, no qual se contextualiza a enfermagem francesa do fim do século XIX ao início do século XX, mais especificamente do período de 1870 a 1914, bem como do período de 2005 a 2009, em que se destacam as recentes mudanças que a profissão passa naquele país. Como fontes documentais, utilizamos seis periódicos de enfermagem franceses, editados entre junho de 2005 a junho de 2006, nos quais foram selecionados sete artigos que tratavam especificamente do histórico da enfermagem profissional francesa e perspectivas atuais da profissão. Foram selecionados também cinco livros produzidos por enfermeiros e por historiadores franceses, tratando principalmente da história da profissionalização da enfermagem francesa no final do século XIX. Outras fontes também serviram como consulta, como a legislação pertinente à temática, incluindo a Lei ${ }^{\circ} 1668$ de 21 de dezembro de 2006 e decretos $\mathrm{n}^{\mathrm{o}} 552$ e $\mathrm{n}^{\mathrm{o}} 1571$ do ano de 2007, que tratam da criação da Ordem Nacional de enfermeiros, o decreto $\mathrm{n}^{\circ} 221$ de 1993 e $\mathrm{n}^{\mathrm{o}}$ 11-28-802, de 2004, relativos às normas e atos da profissão de enfermagem, além de materiais impressos e on-line das Associações de Enfermagem francesas acerca de sua história. O período de coleta de dados foi entre o ano de 2006 a 2009.

As fontes históricas são obtidas por meio de registros, encontradas em livros, revistas, jornais, cartas, diários, atas de reuniões, processos judiciais, entre outros. As fontes são fundamentais para construir a história, possibilitam realizar a análise dos dados, e permitem confirmar e/ou rejeitar hipóteses, de modo a garantir a objetividade e a intersubjetividade da pesquisa. ${ }^{6}$

Para análise dos dados, utilizou-se a análise documental de Bardin, ${ }^{7}$ que tem por objetivo representar de outra forma a informação que consta nos documentos, permitindo transformar um documento primário em secundário. $\mathrm{O}$ objetivo da análise documental é a representação condensada da informação, para consulta e armazenagem, em que a operação intelectual, como o recorte da informação e divisão em categorias, se reproduz de igual forma em relação ao tratamento das mensagens na análise de conteúdo, tendo como diferença que a análise de conteúdo trabalha com mensagens e comunicação, enquanto a segunda trabalha com documentos. Deste modo, a partir da classificação e análise dos textos e documentos pesquisados, buscamos interpretar os principais fatos que marcaram e têm marcado a história da enfermagem francesa, $\mathrm{o}$ que nos permitiu construir três categorias temáticas, as quais apresentamos: A enfermagem moderna na
França: a influência republicana; O modelo Nightingale na França; e A educação em enfermagem na atualidade: novas perspectivas.

\section{A enfermagem moderna na França: a influ- ência republicana}

O período moderno da profissionalização da enfermagem na França iniciou-se a partir de 1870, e se desenvolveu sob influência de correntes de pensamento divergentes, trazendo repercussões até os dias atuais. Para uma melhor compreensão desta historicidade, é necessário nos reportarmos inicialmente a duas questões fundamentais: a instalação da terceira república (1870-1940) e sua política anticlerical, bem como a entrada da profissão médica no ambiente hospitalar. A partir destes eventos, passou-se a proclamar a crença no progresso, no positivismo, na educação democrática, na revolução industrial, na ciência e, sobretudo no anti-clericalismo, e como resultado iniciou-se um laicismo progressivo das instituições, como a escola e o hospital, na época dominados pela igreja. Entre os defensores de uma república laica e principalmente do anti-clericalismo na instituição hospitalar, atuou o médico, jornalista e parlamentar Désiré Magloire Bourneville (1840-1909), sustentando que o laicismo do hospital era não somente uma necessidade, como também um dever cívico. ${ }^{8-9}$

A entrada da profissão médica na instituição hospitalar tem origem na modernização do hospital, que passa a exercer a função terapêutica, em detrimento daquela de caridade e acolhimento dos excluídos da sociedade. O hospital passa a ser local de aprendizado para estudantes de medicina, e progressivamente o corpo médico assume espaços na instituição, começando pelo papel científico e técnico, até o administrativo. Com a institucionalização da clínica, as relações de poder se estabelecem a partir da prática médica, e permanecem determinando e imprimindo sua marca no dia a dia das relações sociais. O desenvolvimento do trabalho da enfermagem e demais profissões da área de saúde, bem como a forma como as relações de saber/poder se estabelecem, foram historicamente construídos por esta transformação das relações no interior do hospital. Foucault acrescenta que, "pela disciplinarização do espaço médico, pelo fato de se poder isolar cada indivíduo, colocá-lo em um leito, prescrever-lhe um regime, etc., pretende-se chegar a uma medicina individualizante. Efetivamente, é o indivíduo que será observado, seguido, conhecido e curado. $\mathrm{O}$ indivíduo emerge como objeto do saber e da prática médica". ${ }^{10: 111}$ 
Quando os médicos percebem o quanto o espaço hospitalar pode ser um espaço de poder e saber, estes introduzem uma nova ordem no cotidiano do hospital e, consequentemente, excluem do espaço de decisão aqueles que antes detinham o poder, suplantando-os e lhes "confiando um papel determinado, mas subordinado". ${ }^{11: 166}$

E quem eram essas pessoas? Eram leigas e faziam o trabalho elementar no hospital, ou senhoras da sociedade que prestavam trabalhos caritativos como as Senhoras da Confraria da Caridade, ou as religiosas de algumas ordens religiosas, como as Agostinianas ou também as Irmãs de Caridade, que condizendo com a sua condição de servir ao próximo abnegadamente, prestavam os cuidados aos doentes e deste modo, acatavam esta transformação da forma submissa para a qual haviam sido preparadas pela formação religiosa recebida.

As irmãs de Caridade haviam se multiplicado nas instituições hospitalares francesas desde o século XVII, ocupando-se das atividades de cuidado dos doentes, bem como administrativas. Entre o corpo médico e a ordem religiosa, surgiram oposições em vários segmentos, como a definição do orçamento institucional e prioridade de investimentos, as diferentes concepções em relação à doença, bem como concepções morais divergentes, especialmente no que se refere ao sexo e à loucura. ${ }^{12}$ Neste contexto, buscou-se uma solução para esta problemática que se apresentava como entrave ao progresso médico da época, culminando na reivindicação, por parte do corpo médico, de um novo pessoal para assistir aos doentes no hospital, que fosse recrutado e formado para esta função, porém obrigatoriamente submisso. Neste sentido, o anti-clericalismo e a forte implicação da profissão médica na política criam rapidamente a "enfermeira" como um novo tipo de cuidadora. ${ }^{8}$

A concretização deste projeto acontece no ano de 1878, com a criação da "Escola de formação para os enfermeiros e enfermeiras da Assistência Pública", no Hospital Salpêtrière, em Paris, tendo o médico Bourneville como seu principal idealizador. Apesar do nome da escola ter duplo gênero, masculino e feminino, as mulheres eram preferidas aos homens, pois assim como a teologia e a medicina era um campo de saber dominado por homens, a função de cuidadora era entendida como sendo uma atividade feminina. ${ }^{8,13-14}$

Bourneville utiliza algumas idias das teorias de Nightingale, porém com algumas ressalvas, que permitiam que este "modelo" de enfermeira fosse particularmente diferente daquele modelo anglo- saxônico. Dentre as diferenças estava a exigência por um comportamento interditado de iniciativas, de tal modo que esta enfermeira seria uma eterna auxiliar, devendo apenas executar. Esta formação era direcionada a "mulheres do povo", sem instrução, que de algum modo atendiam ao perfil esperado para a enfermeira idealizada para este modelo submisso e subalterno ao médico. O projeto de Bourneville busca formular a enfermeira ideal, criando-se um modelo republicano, contando como requisitos principais aqueles de devotamento e competência. O devotamento deixa de ser dedicado a Deus ou à igreja, mas sim à república e à Assistência pública, assim como à ciência e ao corpo médico. A competência era subsidiada por uma instrução primária (saber ler e escrever) e uma instrução profissional (formação elementar sobre anatomia, fisiologia, nomenclaturas sobre instrumentos cirúrgicos, medicamentos). Esperava-se que a nova enfermeira fosse uma "santa laica", com as seguintes características: ser capaz de substituir o médico na observação e administração dos tratamentos, sem jamais modificá-los; ter uma moral exemplar, a fim de romper com a má reputação dos cuidadores laicos; ser laica, a fim de não ser controlada pela hierarquia religiosa mantida nos hospitais; ser dedicada ao médico e ao doente; ser sobretudo uma mulher, pois os comportamentos sociais da mulher da época eram compatíveis com aqueles esperados para uma enfermeira. ${ }^{8-9,13}$

Ao analisar e refletir sobre os diferentes aspectos que se referem ao "dever ser" da enfermeira, facilmente podemos relacioná-los ao que se "espera" da mulher, isto é, que seja cumpridora dos deveres, devotada, honesta, disciplinada, submissa e abnegada. São papéis historicamente construídos como se fossem elos de uma mesma corrente que precisa ser reconhecida e reconstruída para auxiliar na compreensão da realidade atual e assim possibilitar novas rupturas com vistas à transformação da mesma. ${ }^{15}$

O anti-clericalismo radical de Bourneville vai lhe render numerosos inimigos, entre eles, Anna Hamilton e Léonie Chaptal, que o criticam severamente afirmando que o projeto de formação das enfermeiras foi reduzido a uma necessidade política. ${ }^{8-9,13}$

\section{O modelo Nightingale na França}

A profissionalização da enfermagem francesa contou também com outros personagens, que defendiam uma formação para enfermeiras que seguisse o modelo anglo-saxônico, entre eles Anna Hamilton (1864-1935), uma médica que defendeu 
em sua tese de medicina a primeira obra francesa sobre as enfermeiras, intitulada "Considerações sobre as enfermeiras dos hospitais", sustentando a necessidade de uma formação de alto nível para os gardes-malades* franceses, no ano de 1898. Após viajar pela Europa para observar os cuidadores práticos nos hospitais e ter conhecido o trabalho de Florence Nightingale em Londres, Anna Hamilton passou a defender a implantação do sistema Nightingale na França. Hamilton critica severamente o modelo republicano de Bourneville, adotado pela Assistência Pública dos Hospitais de Paris, como sendo um modelo com uma concepção empobrecida para as funções de enfermeira, reduzindo esta função àquela compatível ou inferior à de doméstica. Como diretora da Casa de Saúde Protestante de Bordeaux, Anna Hamilton implantou, em 1902, o modelo de hospital-escola defendido por Nightingale, chamado "Escola profissional de assistência aos doentes". Tratava-se de uma escola privada, onde as alunas consagrariam dois anos de seus estudos. Quanto ao nível social das alunas, Anna Hamilton defendia que a enfermeira deveria ser recrutada dentro da mesma classe dos médicos, cujas alunas deveriam ser "mulheres de educação", com alto nível social, escolar e cultural. ${ }^{13-14}$

Outras escolas de enfermagem foram criadas de acordo com o modelo anglo-saxônico, como a de Léonie Chaptal (1873-1937), primeira enfermeira jornalista e escritora, que obteve o diploma de dama enfermeira vigilante de primeiro grau, remetido pela Sociedade de Socorro aos Militares Feridos (1899), e também de enfermeira hospitalar dos Hospitais de Paris, remetido pela Escola de Bourneville (1903). Em 1905, Léonie Chaptal participou da criação de uma escola de enfermeiras chamada "A casa-escola de Enfermeiras", onde exerceu a função de diretora até 1909. Já nesta época, esta reivindicava o reconhecimento de uma função própria para as enfermeiras, acrescentando também que a enfermeira de saúde pública teria a missão de "instruir ao mesmo tempo que cuidar, prevenir ao mesmo tempo que curar" ${ }^{14: 28}$

Léonie Chaptal foi considerada como precursora da enfermagem moderna na França, com a preocupação constante de formar enfermeiras educadoras em saúde, recebendo destaque por colaborar de maneira significativa com os programas de formação nacional e a regulamentação do exercício da profissão. A partir de suas publicações, o governo francês iniciou a regulamentação sobre a profissão de enfermagem (1921), criando um programa de formação nacional de dois anos para as enfermeiras, fornecendo um diploma reconhecido pelo estado francês e criando um Comitê de aperfeiçoamento das Escolas de Enfermagem. Em 1923, Chaptal colaborou ativamente para o lançamento da primeira revista de enfermagem francesa denominada de: "A enfermagem francesa". Em 1926, publicou a primeira coleção de obras destinada às enfermeiras, intitulada "A biblioteca de enfermagem", que passou a ser utilizada posteriormente nas escolas de enfermagem até a década de $60 .{ }^{13-14}$

As primeiras escolas profissionais se desenvolveram na França tendo por base modelos diferentes e convergentes, resumindo-se no modelo republicano instituído nas Escolas da Assistência Pública de Paris, e no modelo nightingaleano distribuído pela província da França, ou seja, em todo o Sudoeste francês, como Bordeaux, Cambrai, Elbeuf, Dijon, Lorient. Considera-se, portanto, que o período compreendido entre 1870 e 1914 caracterizou-se como o período moderno da profissionalização da enfermagem na França. Neste, foi oficializada a profissão de enfermeira, definido seu papel, bem como a concepção de sua prática, apesar de toda uma ideologia ligada a valores religiosos e morais herdados de um passado religioso que contribuíram sobremaneira para a construção de uma profissão auxiliar do corpo médico. ${ }^{16}$

No período entre 1914 e 1922, por ocasião da Primeira Guerra Mundial, a enfermagem francesa, aliada à Cruz Vermelha Francesa, prestou importante suporte aos hospitais, fornecendo cerca de 63.150 enfermeiras para atuarem nos hospitais civis e militares. Ao mesmo tempo, a Cruz Vermelha Americana enviou à Europa enfermeiras americanas, que ao chegarem à França, se surpreenderam por não encontrar, neste país, centros de saúde semelhantes àqueles que existiam nos Estados Unidos, onde os cuidados de enfermagem em saúde pública ocupavam lugar de destaque. A partir do suporte financeiro de instituições filantrópicas americanas, bem como da presença e influência destas enfermeiras no cenário francês, passou a ocorrer o desenvolvimento da enfermagem em saúde pública, bem como a formação de Enfermeiras visitadoras da infância e da luta contra a tuberculose. Neste período se desenvolveram estruturas sanitárias que tinham como objetivos o combate à mortalidade infantil, o tratamento da tuberculose, formando assim o primeiro esboço de um serviço de saúde pública no país. Gradativamente foram

* Denominação dada na época à pessoa que cuida dos doentes.

Texto Contexto Enferm, Florianópolis, 2010 Abr-Jun; 19(2): 325-33. 
sendo acrescentados outros serviços, como o tratamento de doenças venéreas, os dispensários de doenças mentais e os serviços de higiene escolar. Porém, apesar do crescimento do serviço de saúde pública, o impacto da medicina hospitalar e a contínua dependência da enfermagem frente ao corpo médico fizeram com que, pouco a pouco, houvesse um recuo da enfermagem nesse setor, reduzindo seu campo de ação profissional. Ao invés disso, a enfermagem francesa passou a atuar mais no meio hospitalar, contribuindo cada vez mais para o desenvolvimento de uma medicina curativa, em detrimento da preventiva. ${ }^{14}$ Este fato repercute até os dias atuais, visto que no final do século XX, cerca de $73 \%$ da categoria de enfermagem francesa atuava no campo hospitalar. ${ }^{17}$

\section{A educação em enfermagem francesa na atualidade: novas perspectivas}

Atualmente na França, a educação em enfermagem é ministrada pelos Institutos de Formação de Cuidados de Enfermagem (IFSI), com duração de 37 meses entre estudos teóricos e práticos, com estágios em hospitais desde o primeiro ano de formação, e obtenção no final do curso do Diploma de Estado de Enfermeiro. Para ascender à carreira, o profissional pode optar por formação complementar de Cadre de santé (gestor de saúde), agregando competências de administração e ensino; Cadre supérieur de santé (gestor de saúde de nível superior), com funções de responsabilidade administrativa superior; ou Directeur de soins, (diretor de cuidados) com competência para direção geral de enfermagem em uma instituição. A partir da formação de Cadre de santé, é possível também uma formação universitária, onde cinco mestrados profissionalizantes são propostos: Economia e organização de estabelecimentos hospitalares; Organização de unidades de produção de cuidados; Pedagogia; Organização e Logística; ou Master cadre expert qualité (mestrado no quadro de perito em qualidade). Pode-se também fazer a opção por algumas especializações (com diploma reconhecido pelo estado) em: enfermagem em bloco operatório, enfermeiro anestesista e enfermagem em puericultura. A formação contínua tanto é oferecida em cada hospital, no centro de formação continuada da instituição, quantonos Institutos de formação de "Cadres de santé". 18

A implantação do sistema LMD, se remete ao acordo de Bolonha de 1999, que engloba atualmente 45 países e visa padronizar os diplomas de ensino superior na Europa, sendo que na França a implantação deste sistema ocorreu no ano de 2002. Em relação à enfermagem francesa, o currículo atual não oferece possibilidades de acessar este sistema, o que fragiliza significativamente o campo de pesquisa nesta área. A implantação do sistema LMD para a enfermagem significa a abertura de uma via universitária que permita a realização de mestrados voltados para o plano profissional ou para o desenvolvimento de pesquisas, bem como o doutorado. Esta proposta vem ao encontro da proposta da prática de enfermagem avançada, uma vez que é recomendada que a formação para esta prática seja o mestrado. Esta reestruturação curricular implica na integração destes cursos junto às universidades francesas. ${ }^{19}$

Quanto à adoção da prática de enfermagem avançada, inúmeros estudos têm apontado que nos próximos anos haverá uma diminuição pronunciada de médicos, que acabará por comprometer a assistência no sistema de saúde francês. Em abril de 2003, o Ministro da Saúde confiou ao Professor Yvon Berland, Reitor da Faculdade de Medicina de Marseille, uma missão de estudos e propostas em relação à organização de cuidados em saúde e as possíveis cooperações a serem desenvolvidas entre os diferentes profissionais da saúde, a fim de reorganizar a assistência em saúde. Deste modo, foi publicada a Relação Berland, um documento que sugere a transferência de competências de atividades médicas aos profissionais paramédicos. Este estudo recomenda que a formação dos atores paramédicos susceptíveis a aceitar a transferência de competências deve rapidamente se inscrever na grade LMD. Em relação à enfermagem, este estudo baseia-se na experiência de países como Estados Unidos, Canadá e Reino Unido, apontando a necessidade de formar enfermeiras com uma prática de enfermagem avançada, tal como nestes países, para que possam assumir esta transferência de competências. É desejável criar a função de Enfermeira clínica especialista, onde após três anos de estudos para obtenção do Diploma de Estado de Enfermeira, estas possam ascender a um nível de formação de mestrado, que se declinaria em três opções: Gestão, Formação e Cuidado. ${ }^{20}$ Este tema vem sendo tratado com polêmica, visto que a classe médica tem defendido que aconteça uma delegação de tarefas ao enfermeiro, sob prescrição e supervisão médicas. Os órgãos representantes da enfermagem aprovam a incorporação de novas competências, mas lembram da necessidade de uma formação que atenda a estas novas perspectivas, reivindicando que as novas competências sejam incorporadas com verdadeira autonomia. ${ }^{19}$ 
Com este propósito, desde o ano de 2006 vem sendo construído um referencial de formação para a enfermagem que seja compatível com o sistema LMD. Esta reforma tem sido conduzida pela Direção de Hospitalização e Organização de Cuidados (DHOS), ligada ao Ministério da Saúde. Este grupo de trabalho écomposto por especialistas que buscam construir um referencial de formação que forme uma enfermeira com destaque para sua competência clínica, incluindo no ensino disciplinas como psicologia, sociologia, processos patológicos, ciências e técnicas de enfermagem, ética profissional, além do ensino do inglês e das tecnologias de informação e comunicação, integradas ao currículo. ${ }^{21}$

A implantação deste novo programa de formação deve ocorrer até o ano de 2014, gerando entre profissionais e docentes da área ainda muitas dúvidas quanto a este novo currículo, bem como muitos conflitos e contestações pelo modo como este processo vem sendo conduzido. A discussão da reforma curricular na França não passa apenas pelo desejo da profissão de enfermagem ascender a uma carreira universitária, e, portanto, ter um maior reconhecimento social e científico. A prática de enfermagem clínica e a adoção de novas competências, que serão possíveis através desta reforma curricular, têm suscitado interesses econômicos, pois se pretende, segundo experiências já aplicadas, reduzir cerca de $10 \%$ dos custos médicos e $16 \%$ dos cuidados ambulatoriais. Três fatores são considerados a respeito da eficácia da delegação de competências médicas para a enfermagem: a escala de salários, a produtividade dos diferentes profissionais e o volume de trabalho que pode ser delegado com ou sem supervisão de um médico. Porém, assinala-se também que a falta atual de pessoal no setor de enfermagem, coloca em dúvida a capacidade de a profissão absorver estas transferências de competências. Entretanto, contando com as últimas projeções demográficas para 2020, é esperado um crescimento da densidade de enfermeiros para $24 \%$ e uma redução de médicos de $19 \% .{ }^{19,22}$

Nos últimos trinta anos, de acordo com Poisson $^{12}$, a profissão de enfermagem investiu essencialmente no campo de conhecimentos e práticas voltadas ao exercício médico, demonstrando sua capacidade de exercer plenamente o seu papel de colaboradora da profissão médica. No entanto, no que concerne ao seu próprio papel, aquele que se permite ir além dos limites da doença e avançar nas repercussões que estas situações causam na vida do indivíduo, a enfermagem francesa não tem conseguido elaborar um real conteúdo científico que sustente e dê corpo a este papel. Isto requer um investimento no campo das ciências humanas e sociais, a integração de conhecimentos resultantes do processo de cuidado, bem como o desenvolvimento de pesquisas na área de enfermagem.

É deste modo que, apesar de todas as contradições geradas pelo novo currículo, instituições, sindicatos e autores da área veem com entusiasmo esta possibilidade, pois a formação universitária possibilitaria a construção futura de uma elite universitária e a formação de atores no campo do ensino e da pesquisa, condição necessária para a constituição de uma disciplina. A formação universitária tem várias dimensões: institucional, pedagógica, profissional e internacional. Do ponto de vista institucional, a aproximação dos institutos de formação com a universidade traria benefícios inegáveis. Sob o ângulo pedagógico, a inscrição universitária possibilitaria um percurso de formação diversificado e o desenvolvimento de uma carreira em pesquisa. No plano profissional, espera-se um maior reconhecimento social e um melhor equilíbrio nas relações de trabalho entre os profissionais de saúde. A dimensão internacional viria com uma maior visibilidade da profissão, a ampliação de oportunidades aos estudantes e profissionais. ${ }^{22}$

Atualmente, sinalizam-se outras mudanças para a profissão, que se colocam como conquistas e desafios para os profissionais que lá atuam, como a recente criação do Conselho Nacional da Ordem dos Enfermeiros. A criação deste órgão significa, para a enfermagem francesa, a formação de um Conselho Nacional que represente os cerca de 510 mil profissionais de enfermagem que atuam nesse país, visto que no sistema atual a representatividade da profissão é dividida por mais de 150 associações ou sindicatos profissionais, onde apenas $4 \%$ dos enfermeiros são sindicalizados e $8 \%$ deles pertencem a alguma associação de classe. A criação deste conselho foi reivindicada por Associações de Enfermagem há vários anos, e encontra-se atualmente em processo de implantação. Em 14 de janeiro de 2009 foi eleita a primeira presidente do Conselho Nacional, seguindo-se o processo de eleição dos presidentes regionais. Uma das prioridades do Conselho Nacional da Ordem dos Enfermeiros é a elaboração do código de deontologia da profissão. ${ }^{19-5}$

\section{CONSIDERAÇÕES FINAIS}

Através deste estudo, pode-se perceber que, entre o século XIX e a primeira metade do século $\mathrm{XX}$, a enfermagem francesa sofreu uma gradativa 
transformação, em que inicialmente a profissão tinha como referência a religião, sendo substituída por profissionais que desenvolveram saber e competência, sob diferentes correntes de pensamento e com diferentes objetivos, a exemplo do modelo republicano e nightingaleano. A profissionalização da enfermagem passou a ser laica, com uma ética humanista, porém a imagem tradicional do papel da mulher, de santa e servil, prevaleceu por longo período de tempo.

Em busca de uma identidade profissional, surgiram, no final do século XIX, as primeiras associações de enfermeiros e enfermeiras, bem como publicações específicas na área, ainda que sua difusão e implantação envolvessem apenas uma minoria dos profissionais, desenvolvendo um papel ainda pouco relevante na época. Pouco a pouco, certos valores adquiriram importância: o sentido da equipe cuidadora, o indispensável cuidado ao doente, a criação recente do "diagnóstico de enfermagem". ${ }^{12}$

A partir da produção de enfermeiros e historiadores voltados à temática, percebe-se que a enfermagem francesa luta para livrar-se de uma herança de um passado recente, adquirida ainda durante a profissionalização da enfermagem moderna na França, marcando a profissão de modo predominante como auxiliar da profissão médica, em detrimento do desenvolvimento do seu próprio papel de cuidadora. Com o passar do tempo, a enfermagem francesa tem buscado avançar tanto no sentido assistencial quanto acadêmico, buscando colocar a profissão no patamar de outras carreiras de nível superior. Isto se configura como algo positivo em todos os sentidos, tanto nacional quanto internacionalmente, entendendo-se que a interlocução entre os países poderá se ampliar, assim como o mercado de trabalho.

Porém, é necessário considerar também que a implantação de um novo currículo para enfermagem com o desenvolvimento de novas competências vem atender a interesses não apenas voltados à profissão, mas atender a uma situação de carência de profissionais médicos naquele país que já é uma realidade e que tende a agravar-se nos próximos anos. A divergência entre associações, escolas de formação e profissionais que participam deste momento histórico, surge do receio que esta nova realidade para a profissão possa tomar rumos ainda não muito claros, que hora parecem tender para o desenvolvimento da profissão para uma maior autonomia, reconhecimento social e desenvolvimento acadêmico, hora para uma repetição da história, recriando a enfermeira como uma auxiliar do corpo médico, absorvendo novas competências sem a autonomia necessária, confirmando sua dependência ao corpo médico e mais uma vez não assumindo e desenvolvendo seu próprio papel.

A partir da realidade apresentada, compreendemos que, para que efetivamente a profissão da enfermagem avance naquele país, faz-se necessário que as enfermeiras francesas busquem construir um real conteúdo científico que sustente e dê corpo à profissão e ao papel desempenhado por estas. Isto requer um grande investimento na produção de conhecimentos específicos acerca do cuidado, no campo das ciências humanas e sociais, e sua integração, bem como o desenvolvimento de pesquisas na área de enfermagem, fazendo com que a profissão e as profissionais possam ser reconhecidas, indo além do trabalho que vêm desempenhando até o momento.

\section{REFERÊNCIAS}

1. Padilha MICS, Borenstein MS. História da Enfermagem: ensino, pesquisa einterdisciplinaridade. Esc Anna Nery. 2006 Dez; 10(3):532-8.

2. Padilha MICS. A mística do silêncio: a enfermagem na Santa Casa de Misericórdia do Rio de Janeiro no século XIX. Pelotas (RS): UFPEL; 1998.

3. Espírito Santo TB. Enfermeiras francesas na capital do Brasil (1890-1895) [dissertação]. São Paulo (SP): Escola de Enfermagem da Universidade de São Paulo; 2008.

4. Courtois AC, Courtois R, Cuminet L, Grandsire A. Quelle est l'image de l'infirmière aujourd' hui? Soins. 2005 Nov; 700:41-7.

5. Isambart G. Interview exclusive de la première présidente de l'ordre des infirmiers, Dominique Le Boeuf. In: Infirmiers.com. [atualizado 2009 Jan; acesso 2009 Fev 19]. Disponível em: http:/ /www. infirmiers.com/inf/reconnaisance/dominique-leboeuf-presidente-ordre-infirmier.php

6. Padilha MICS, Borenstein MS. O método de pesquisa histórica na enfermagem. Texto Contexto Enferm. 2005 Out-Dez; 14(4):575-84

7. Bardin, L. Análise de Conteúdo. Lisboa (PT): Edições 70; 2004.

8. Debout C. La profession infirmière en France: du projet medical a l'emergence d'un projet disciplinaire infirmier. Soins. 2005 Nov; 700: 36.

9. Leroux-Hugon V. Des saintes laiques: les infirmières à l'aube de la troisiéme republique. Paris (FR): Sciences em Situation; 1992.

10. Foucault M. Microfísica do Poder. $22^{\mathrm{a}}$ ed. Rio de Janeiro (RJ): Graal; 2006.

11. Foucault M. Vigiar e punir. $6^{\mathrm{a}}$ ed. Petrópolis (RJ): Vozes; 1987 
12. Goubert JP. Iniciation a une nouvelle histoire de la medicine. Paris (FR): Ellipses; 1998

13. Poisson M. Origenes républicaines d'un mòdele infirmier (1870-1900). Vincennes (FR): Editions Hospitaliéres; 1988.

14. Girault V, Bellon R. Dates et figures marquantes de la profession infirmière. Soins. 2005 Nov; 700: 31-40.

15. Padilha MICS, Borenstein MS. La enfermería en el Brasil del siglo XIX: un análisis historiográfico. Temperamentum (Granada) 2006; 3(1):356-60.

16. Collière MF. La profession infirmière em quête de son histoire 1870-1980. Rev Infirm. 1980 Dez; 3(10):13-24.

17. Duboys-Fresney C. Radioscope de la profesión infirmiére à l'aube du XXéme siècle. Résumés du Congreso de Nantes [online]; 22 Mars 2006; Nantes. 2006 [acesso 2008 Fev 18]. Disponível em: http://associdees.canalblog.com/docs/Congr_s_ NantesRecueil_r_sum_s_version_14mars06.pdf.

18. Instituts de Formation en Soins Infirmiers de L'APHP [acesso 2009 Fev 19] Disponível em: http:/ / formation.aphp.fr/doc/fiches_metiers/infirmier.pdf

19. Nys JF. L'elargissement dês compétences dês infirmières: l'exemple britannique. Soins cadres de santé. 2006 Mai; (24):28-30.
20. Berland, Y. Cooperation des professions de santé: lê transfert dês taches et de competences. In: La Fédération des Praticiens de Santé [homepage na Internet]. Paris, 2003 [acesso 2009 Jan 19]. Disponível em: http://www.la-fps.fr/transfert_competence_ BERLAND2003_fps.pdf.

21. Clément J. Comprendre la réforme de la formation infirmière. In: Infirmiers.com [homepage na Internet]. [atualizado 2009 Jan; acesso 2009 Fev 19]. Disponível em: http:/ / www.infirmiers.com/doss/ comprendre-reforme-infirmiere.php

22. Hémery P. "Infirmière experte": aux frontières entre lês professions. In: Staffsanté [homepage na Internet]. [acesso $2009 \mathrm{Fev}$ 19] Disponível em: http://www.staffsante.fr/contenus/dossiers/ partie/4/infirmiere-un-metier-en-evolution.

23. Schweir FX. L'universitarisation de la formation des soins infirmiers en France: une opportunité pour les professionels, les usarges et le developpement de la santé publique? Résumés du Congreso de Nantes [online]; 22 Mar 2006; Nantes. 2006 [acesso 2008 Fev 18]. Disponivel em: http://associdees. canalblog.com/docs/Congr_s_NantesRecueil_r_ sum_s_version_14mars06.pdf

E-mail: isabel.alves07@yahoo.com.br 